LINKS FOR WEB:

OMIM: http://www.ncbi. nlm.nih.gov/entrez/query. fcgi? db=OMIM

CFC:

http://www.ncbi.nlm.nih. gov/entrez/dispomim. cgi?id=115150

Noonan:

http://www.ncbi.nlm.nih. gov/entrez/dispomim. cgi?id $=163950$

Costello: http://www.ncbi.nlm.nih. gov/entrez/dispomim. cgi?id $=218040$

Entrez: http://www.ncbi. nlm.nih.gov/entrez/query. fcgi? $\mathrm{db}=$ gene

$B R A F$ :

http://www.ncbi.nlm.nih. gov/entrez/query.fcgi? $\mathrm{db}=$ gen e\&cmd=Retrieve\&dopt=full_ report\&list_uids $=673$

MAP2K1: http://www.ncbi.nlm nih.gov/entrez/query.fcgi? $\mathrm{db}=\mathrm{g}$ ene\&cmd=Retrieve\&dopt $=$ full _report\&list_uids=5604

MAP2K2: http://www.ncbi.nlm. nih.gov/entrez/query.fcgi? $\mathrm{db}=\mathrm{g}$ ene\&cmd=Retrieve \&dopt=full _report\&list_uids $=5605$

KRAS: http://www.ncbi.nlm. nih.gov/entrez/query.fcgi? $\mathrm{db}=\mathrm{g}$ ene\&cmd=Retrieve \&dopt=full _report\&list_uids=3845

HRAS: http://www.ncbi.nlm. nih.gov/entrez/query.fcgi? $\mathrm{db}=\mathrm{g}$ ene\&cmd=Retrieve \&dopt=full _report\&list_uids $=3265$

PTPN11: http://www.ncbi.nlm. nih.gov/entrez/query.fcgi? $\mathrm{db}=\mathrm{g}$ ene\&cmd=Retrieve\&dopt $=$ full _report\&list_uids $=5781$
HUMAN DISEASE

\section{Why crawl when you can leap?}

Any incremental step in our understanding of common, multifactorial diseases causes much excitement, but the flurry of research in this area risks obscuring the importance of monogenic disorders, the biological insights that mapping rare diseases can bring, and the often causative nature of the mutations that are found. A case in point is the unexpected finding that a rare disorder called cardio-facial-cutaneous syndrome (CFC) is caused by mutations in the Ras-MAPK pathway, which is best known for its involvement in cancer.

Children with CFC are developmentally delayed and have characteristic cranio-facial features, cardiac defects and skin abnormalities. Although CFC was diagnosed back in 1986, nothing was known about its genetic basis, the only hint being a phenotypic similarity between CFC and two other disorders, Noonan syndrome and Costello syndrome. These diseases are caused by mutations in two components of the Ras-MAPK pathway (PTPN11 and HRAS, respectively) - a conserved signalling cascade that transmits extracellular signals into the nucleus and, when mutated, leads to runaway cell proliferation and so to cancer. The phenotypic connection prompted two groups - one led by Katherine Rauen and the other by Yoko Aoki - to see whether mutations in Ras-MAPK components could also be at the root of CFC, a chase that was successfully over in just a matter of weeks.

Unlike other, more celebrated monogenic diseases, such as cystic fibrosis, CFC is rare - it affects only 300 patients - so testing the authors' theory could have taken much time and effort. Thankfully, a support group of patients and their families had set up a biobank of medical records and DNA samples from the affected children, which Rauen and her group used to obtain the material they needed. All but two of the cases studied by Rauen's group had sporadic missense mutations in $B R A F$ $(18 / 23)$ or MAP2K1/MAP2K2 (3/23) - two transducers of MAPK signalling. Aoki and colleagues also found $B R A F$ mutations (in $16 / 43$ patients), with three cases having mutations in KRAS.

The fact that most cases of CFC were caused by mutations in Ras-MAPK signalling establishes a role for the pathway in human development, as well as aiding the diagnosis of CFC. The connection of CFC with such a notorious pathway might bring unexpected benefits, as drugs that are being targeted against cancerous mutations in this pathway could be used to alleviate or even cure the symptoms of CFC. These studies also highlight another important issue - given the predominance of rare disorders among the unmapped monogenic diseases, there is an urgent need for incentives to create biobanks of the kind that were so crucial in these studies.

Tanita Casci

\section{ORIGINAL RESEARCH PAPERS}

Rodriguez-Viciana, P. et al. Germline mutations

in genes within the MAPK pathway cause

cardio-facio-cutaneous syndrome. Science 26 January 2006 (doi:10.1126/science.1124642)

Niihori, T. et al. Germline KRAS and BRAF

mutations in cardio-facio-cutaneous (CFC)

syndrome. Nature Genet. 12 February 2006

(doi:10.1038/ng1749)

FURTHER READING Tartaglia, M. et al. Exclusion

of PTPN11 mutations in Costello syndrome:

further evidence for distinct genetic etiologies

for Noonan, cardio-facio-cutaneous and Costello

syndromes. Clin. Genet. 63, 423-426 (2003)

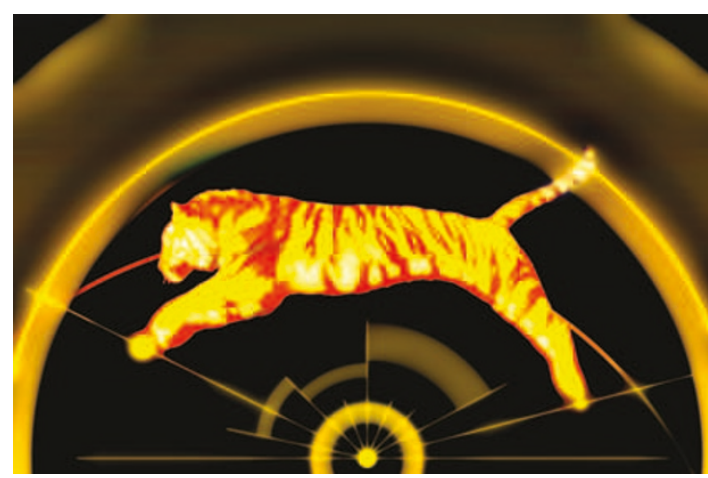

